\title{
The Invisible Pandemics
}

\author{
Marcela Almeida ${ }^{1}[$
}

Received: 17 June 2021 / Accepted: 20 September 2021 / Published online: 2 October 2021

(c) Academic Psychiatry 2021

Beeping monitors

Screaming sirens

Howls of mourning

Conceal

Gloomy young eyes before cold screens

Little children in grueling solitude

Outcast souls who weep alone

Weary teens in sedentary bodies

Inebriated by helplessness, crave affection

Miss rites of passage

And learn to self-mutilate

Exhausted women

Abused and forsaken

Incredulous but faithful

Juggling yet inert

\section{Poet's Statement}

This poem reflects on the many hardships that women, children, and adolescents have had to endure for over one year in the context of school closures. Some of the most vulnerable segments of society were instantly forced to develop adaptive strategies and to put their resilience and coping strategies to a test that often led to negative outcomes.

Remote education has exacerbated the already existing disparities and has contributed to a significant mental health crisis. Women, particularly mothers and single mothers, have been disproportionately impacted, making Herculean efforts to juggle their multiple responsibilities. Carrying the bulk of childcare and eldercare, many women downshifted their careers or left the workforce altogether. Female unemployment rates peaked at unprecedented levels. Domestic violence surged.

Migrants and minorities, children with disabilities and special needs, and teenagers have been particularly affected by social deprivation, unhealthier habits, unstructured routines, and difficult access to important resources that schools traditionally offer.

The deleterious biopsychosocial effects from prolonged school absences are well-established. Nevertheless, in many parts of the globe, schools remained fully or partially closed for over a year, and its long-term psychopathology impact is yet to be known.

It is hoped that this piece will contribute to discourse on a major facet of this pandemic - the mental health impactwhich has been perceived as a secondary matter by many.

\section{Declarations}

Disclosures The author states that there is no conflict of interest.

Publisher's Note Springer Nature remains neutral with regard to jurisdictional claims in published maps and institutional affiliations. 